\title{
VALORES DE REFERÊNCIA DAS PROVAS DE FUNÇÕES HEPÁTICA, RENAL E DE ALGUNS ELETRÓLITOS EM Cebus apella, ANESTESIADOS COM CETAMINA
}

\author{
SERUM BIOCHEMICAL PROFILE OF HEALTHY Cebus apella, \\ ANESTHETIZED WITH KETAMINE
}

\author{
Maria Helena Matiko Akao Larsson ${ }^{1}$ Sílvia Regina Ricci Lucas ${ }^{2}$ Regina Mieko Sakata Mirandola ${ }^{3}$ \\ Paola Lazaretti ${ }^{4}$ José Daniel Luzes Fedulho ${ }^{5}$ Marcelo Alcindo de Barros Vaz Guimarães ${ }^{4}$
}

RESUMO

Foram analisadas 127 amostras de soro sangüíneo, obtidas de macacos-prego (Cebus apella), anestesiados com cetamina. Quantificaram-se as provas de função hepática (proteínas totais, albumina, glicose, bilirrubinas e atividade enzimática de ALT, AST e ALP), de função renal (uréia e creatinina), bem como alguns eletrólitos (sódio, potássio, cloro, cálcio e fósforo). Os valores médios obtidos foram analisados e comparados entre grupos, de acordo com o sexo e a faixa etária. Dentre as provas de função hepática, os valores de ALP e ALT dos animais jovens mostraram-se superiores aos dos adultos, enquanto os níveis de AST foram maiores nos machos jovens em relação aos machos adultos. Os níveis de albumina foram maiores nos machos adultos e fêmeas jovens e a proteína total apresentou valores mais altos nas fêmeas adultas. Relativamente às provas de função renal, os níveis de creatinina mostraram-se maiores nos machos adultos, enquanto os níveis de uréia foram maiores nos machos jovens. Quanto aos eletrólitos, os níveis séricos de cloretos foram superiores nas fêmeas jovens enquanto o sódio mostrou-se mais elevado nos machos adultos do que nas fêmeas jovens.

Palavras-chave: perfil bioquímico, Cebus apella, macaco-prego. SUMMARY

Blood serum samples obtained from 127 Capuchin monkeys, anesthetized with ketamine, were analysed. Hepatic function tests (total protein, albumin, glucose, bilirrubins and enzimatic activity of ALT, AST and ALP), renal function tests (urea and creatinine), and some electrolytes (sodium, potassium, chloride, calcium and inorganic phosphorus) were quantified.
Differences related to sex and age were studied. Among the hepatic function tests, the values of ALP and ALT were higher in the young animals, while the levels of AST were higher in the young males when compared to adult males. The albumin parameters were more elevated in adult males and females than in young males and the total protein showed higher in adult females. In relation to the renal function tests, the levels of creatinine were more elevated in adult males and the urea were more elevated in young males than in adult animals. Chloride were higher in young females while sodium showed more elevated in adult males than young females.

Key words: biochemical profile, Cebus apella, Capuchin monkey.

\section{INTRODUÇÃO}

O macaco-prego (Cebus apella) representa uma das 37 espécies de primatas do Novo Mundo (MARTIN, 1986) e é freqüentemente utilizado como modelo biológico em estudos de zoonoses, como tuberculose (FAKLEN et al., 1983), doença de Chagas (FALASCA $\boldsymbol{e t}$ al., 1990; MALCHIODI $\boldsymbol{e t}$ al., 1993), além de experimentos nutricionais relacionados ao metabolismo de ácidos graxos saturados, níveis de colesterol e triglicérides, bem como suas consequiências na agregação plaquetária (PRONKUK et al., 1991; DIVILLARD et al., 1992; KLOSLA \& HAYES, 1992).

\footnotetext{
${ }^{1}$ Médico Veterinário, Professor Associado, Departamento de Clínica Médica, Faculdade de Medicina Veterinária e Zootecnia (FMVZ), Universidade de São Paulo (USP), Av. Orlando Marques de Paiva, 87, 05508-900 São Paulo, SP. Autor para correspondência.

${ }^{2}$ Médico Veterinário, Professor Assistente, Departamento de Clínica Médica, FMVZ, USP.

${ }^{3}$ Farmacêutico Bioquímico, Técnico Especializado, Departamento de Clínica Médica, FMVZ, USP.

${ }^{4}$ Médico Veterinário, Residente, Hospital Veterinário, FMVZ, USP.

${ }^{5}$ Médico Veterinário, Fundação Parque Zoológico de São Paulo.
} 
A padronização dos valores séricos do macaco-prego é de grande valia para a avaliação adequada de tais estudos, bem como para os que militam na clínica de animais silvestres (FAKLEN $\boldsymbol{e t}$ al., 1983; GRANA et al., 1988).

Ao sentir-se acuado, o macaco-prego tornase agressivo e, sendo assim, o seu manuseio, na maioria das vezes, é feito sob sedação. Pela boa margem de segurança que oferece e por ser viável por via intramuscular, a cetamina é amplamente utilizada na anestesia de símios das mais variadas espécies. Embora BENNET et al. (1992) citem que a cetamina pode causar alterações dos parâmetros hematológicos e bioquímicos em primatas da espécie Macaca mulatta, os valores obtidos de macacos-prego, anestesiados com cetamina, podem ser considerados padrões, pois dificilmente esses espécimes são manuseados sem que estejam sob efeito de algum medicamento.

Visando dar uma contribuição à clínica de animais silvestres, bem como às pesquisas em que o macaco-prego (Cebus apella) é utilizado como modelo biológico e desde que os dados relativos ao assunto, disponíveis na literatura, são escassos, os autores estudaram as provas de funções hepática e renal, bem como os níveis de alguns eletrólitos séricos nos referidos espécimes animais.

\section{MATERIAIS E MÉTODOS}

Foram utilizados 127 animais (Cebus apella) oriundos da Fundação Parque Zoológico de São Paulo, mantidos em recintos com áreas variando entre $20 \mathrm{~m}^{2}$ e $30 \mathrm{~m}^{2}$. A alimentação, fornecida duas vezes ao dia, pela manhã às nove horas e à tarde às quinze horas, era constituída de banana, mamão, laranja, outras frutas da época, batata doce cozida e angu composto de ovos cozidos, pescoço de frango moído e verduras. A refeição vespertina era acrescida de amendoim em casca e destituída de ovos cozidos e pescoço de frango.

Todos os animais utilizados no experimento foram submetidos a um exame clínico prévio e somente aqueles, que não apresentaram nenhuma anormalidade detectável, foram considerados aptos a serem incluídos no presente projeto.

Os animais foram divididos em grupos, segundo sexo e idade; quanto à idade, aqueles que apresentavam dentição decídua foram considerados jovens e aqueles com dentição permanente constituíram o grupo dos animais adultos. Para se proceder à colheita de material (sangue), os animais foram inicialmente anestesiados com cetamina, por via intramuscular, na dose de $10 \mathrm{mg} / \mathrm{kg}$; passados, aproximadamente, 15 minutos, através de venipunc-tura da veia femoral direita e/ou esquerda, colhiam-se 8 a $10 \mathrm{ml}$ de sangue, acondicionado em tubos livres de íons metálicos e, imediatamente, centrifugado para a obtenção de soro destinado à realização das provas bioquímicas.

Os exames bioquímicos realizados, utilizando-se o analisador bioquímico RA-100® (Technicon-Bayer), foram os seguintes:

a) uréia: método da urease/GLDH, em ultra violeta (TIFFANY et al., 1972);

b) creatinina: método de Jaffet modificado (LUSTGARTEN \& WENK, 1972);

c) glicose: método enzimático da glicose oxidase/peroxidase (BHARHAM \& TRINDER, 1972);

d) proteína total: método do biureto (GORNALL et al., 1949);

e) gama-glutamil transferase (GGT): método cinético colorimétrico (SZASZ, 1969);

f) alanina aminotransferase (ALT) e aspartato aminotransferase (AST) (BERGMEYER, 1974): método cinético em ultra-violeta, segundo recomendações da International Federation of Clinical Chemistry (IFCC);

g) fosfatase alcalina (ALP): método cinético colorimétrico, segundo recomendações do Comitê Escandinavo para Enzimologia (SCE) (PENTILLA $\boldsymbol{e t}$ al., 1975);

h) albumina: método de verde de bromocresol, segundo DOUMAS-BIGGS (DOUMAS et al., 1971) modificado.

As determinações séricas de bilirrubina e dos íons fósforo, cálcio, cloro, sódio e potássio foram realizadas manualmente:

a) bilirrubina: método da diazotação manual, segundo JENDRASSIK \& GROF (1938);

b) fósforo: método colorimétrico manual, com molibdato de sódio (BERTI et al., 1987);

c) cálcio: método colorimétrico, com o-cresolftaleína-complexona, sem desproteinização (SARKAR \& CHAUHAN, 1967);

d) cloro: titulação em analisador automático de cloretos da marca CORNING modelo 925 (EISENMAN, 1929);

e) íons sódio e potássio: fotometria de chama (WEISSMAN \& PILEGGI., 1980).

A análise estatística foi realizada utilizandose análise de variância (ANOVA), com intervalo de confiança de $95 \%$, com auxílio do pacote estatístico "SAS-1985"; ao se constatar diferenças significantes estatisticamente, procedeu-se ao teste de Duncan, para se avaliar o grau de significância de tais diferenças. Consideraram-se significantes aqueles resultados que apresentaram $\mathrm{p}<0,05$. 


\section{RESULTADOS}

Os resultados estão apresentados sob a forma de tabelas e expressos em média e desvio padrão. Aqueles referentes à função hepática (proteínas totais, albumina, ALP, ALT, AST, GGT, glicose, bilirrubina total, bilirrubinas direta e indireta), à função renal (uréia e creatinina) e aos eletrólitos (fósforo, sódio, potássio, cálcio e cloro) estão consubstanciados, respectivamente, nas Tabelas 1,2 e 3.

Tabzla I - Prowas de funçà hepática de 127 animais da espécic Cebas apelfa, clinicamente sadios, anestesiados com cetamini, segunda sexu e idade. expressus esa réslia (X) e desvio padrào (DP). S2o Pasto. 1995.

\begin{tabular}{|c|c|c|c|c|}
\hline \multirow{2}{*}{ Pasametros } & \multicolumn{2}{|c|}{ Jovens } & \multicolumn{2}{|c|}{ Adultos } \\
\hline & $\begin{array}{l}\text { Fëneas } \\
X \pm D P(n)\end{array}$ & $\begin{array}{r}\text { Machos } \\
X \pm D I) P(n)\end{array}$ & $\begin{array}{l}\text { Fťmluess } \\
X=D P(n)\end{array}$ & $\begin{array}{l}\text { Machoss } \\
X \pm D P(u)\end{array}$ \\
\hline Alb g/d]* & $\begin{array}{c}4,50 \pm 0,50,(20) \mathrm{a} \\
(3,5-5, \mathrm{i})\end{array}$ & $\begin{array}{c}4,20 \pm 0.50(13) b \\
(3,2-50)\end{array}$ & $\begin{array}{c}4,40 \pm 0,46)(13) \mathrm{ab} \\
(3,4-5,4)\end{array}$ & $\begin{array}{c}4,50 \pm 0,30(51) 3 \\
(3.8-5.3)\end{array}$ \\
\hline ALP UA & $\begin{array}{c}288.80 \div 158.70(19) \mathrm{u} \\
(34,0-599,0)\end{array}$ & $\begin{array}{c}301,10 \div 182,2(12) 0 \\
(72,0+672,0)\end{array}$ & $\begin{array}{c}129,6=64,00(43) 6 \\
{[36,0-293,(1)}\end{array}$ & $\begin{array}{c}200.5=133,6(49) b \\
(31,0-539,0)\end{array}$ \\
\hline ALTUII & $\begin{array}{c}15,0+10,3\langle 19 \mathrm{ja} \\
\{3,0-39,0)\end{array}$ & $\begin{array}{c}13,8=9,1(12) a \\
(5,0-32,0)\end{array}$ & $\begin{array}{c}7,714.8(40) b \\
(1,0-19,0)\end{array}$ & $\begin{array}{l}7,8+4,9(48) b \\
(3,0-31,0)\end{array}$ \\
\hline AST LII & $\begin{array}{c}23,00 * 16,90(17) \text { ab } \\
(5.0-74,0)\end{array}$ & $\begin{array}{c}29,00+13.5(10) a \\
(1,0-18,0)\end{array}$ & $\begin{array}{c}20.60=11,60)(39) \text { ub } \\
(4,0-40,0)\end{array}$ & $\begin{array}{c}38,20+1,3,30(48) h \\
(4,6-81,0)\end{array}$ \\
\hline GGT U/I & $\begin{array}{l}32.60 \pm 12.50(20) \pi \mathrm{t} \\
(13,0-57,0)\end{array}$ & $\begin{array}{c}28.10=8.80(13) \mathrm{a} \\
(9.0 \cdot 40.0)\end{array}$ & $\begin{array}{c}35,80=13,61)(-41) a \\
(15.0-97,0)\end{array}$ & $\begin{array}{c}36.3 n E 18.10(51) a \\
(16.0-108,(0)\end{array}$ \\
\hline Glicese majul & $\begin{array}{l}87,(61)+21), 16(16) a \\
(50,0-139,0)\end{array}$ & $\begin{array}{c}86,30 \pm 23,80(12) a \\
(39,0-138,0)\end{array}$ & $\begin{array}{c}83.40=20.20(41) \mathrm{a} \\
(49.0-142.0)\end{array}$ & $\begin{array}{c}9 B, 80+43,30(45) u \\
(42,0-292,0)\end{array}$ \\
\hline Protcinas totais g/d"* & $\begin{array}{l}7.80 \pm 0.60(20) a b \\
(7.0-9.3)\end{array}$ & $\begin{array}{c}7.10 \neq 0.50(13) b \\
(6.4 \cdot 8.0\}\end{array}$ & $\begin{array}{c}7,80 \div 0,70(-13) \mathrm{a} \\
(6.1-10,1)\end{array}$ & $\begin{array}{c}7.50 \pm 0,70(59)_{a b} \\
(6,0-4,4)\end{array}$ \\
\hline Bilimub, thal myjdf*2* & $\begin{array}{l}0.22 \pm 0.14(10) \\
(0.06-0.5(5)\end{array}$ & $\begin{array}{l}0.16 \pm 0.05(5) \\
(0.09-0.2 !)\end{array}$ & $\begin{array}{c}0.32 \div 0,16(26) \\
(0,04 \cdot 0.81)\end{array}$ & $\begin{array}{c}0.23+0.1 !(18) \\
(0.02-0.52)\end{array}$ \\
\hline Bilimub. dis. mpjoll**** & $\begin{array}{c}0,03 \pm(0,0618) \\
(0,00 \cdot 0,17)\end{array}$ & $\begin{array}{r}0.0710 .01(1) \\
(0.06 \cdot 0.08\}\end{array}$ & $\begin{array}{c}0.09 \div 0,(18(20) \\
(0.02-0.37)\end{array}$ & $\begin{array}{l}0,08 \pm 0,05(15) \\
(0,0011 \cdot(0,170)\end{array}$ \\
\hline Bilirnb, jid, a!g/dlex*ve & $\begin{array}{c}0.10=0.109(8) \\
(0.00 \cdot 0.22)\end{array}$ & $\begin{array}{c}0,1(6 \neq 0,02(3) \\
(0,09-0.13)\end{array}$ & $\begin{array}{c}0.19=0.16(20) \\
(0,0)-0,72)\end{array}$ & $\begin{array}{r}0.13 \neq 0.09(15) \\
(0.019 .0 .033)\end{array}$ \\
\hline \multicolumn{5}{|c|}{ 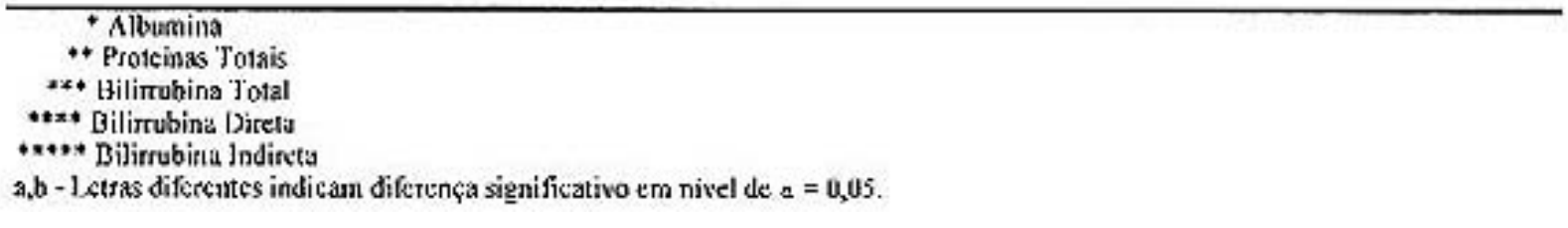 } \\
\hline \multicolumn{5}{|c|}{ 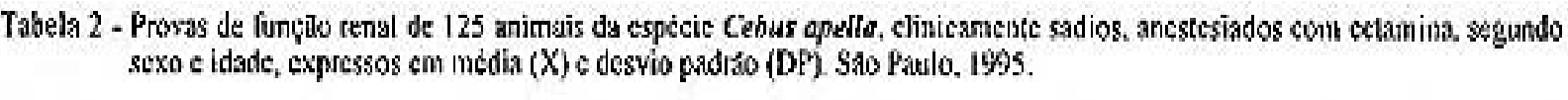 } \\
\hline \multirow{2}{*}{ Perâtietros } & \multicolumn{2}{|c|}{ Jovens } & \multicolumn{2}{|c|}{ Adultos } \\
\hline & $\begin{array}{r}\text { Fenncas } \\
X+1) P(n)\end{array}$ & $\begin{array}{l}\text { Machos } \\
\mathrm{X} \pm \mathrm{DP}(\mathrm{I})\end{array}$ & $\begin{array}{l}\text { Përncas } \\
X \pm D P(n)\end{array}$ & $\begin{array}{l}\text { Machos } \\
X \pm D P(1)\end{array}$ \\
\hline Uréia megjal & $\begin{array}{l}32.6 \pm 10.0(19) a b \\
(25,0-59,0)\end{array}$ & $\begin{array}{l}54.1+15.9(11) \mathrm{a} \\
(31,0-81,(0)\end{array}$ & $\begin{array}{l}39,2 \pm 13,9(40) b \\
(13.0 \cdot 90,0)\end{array}$ & $\begin{array}{c}39,4+18,0)(43) 6 \\
(23,0 \cdot 113.0)\end{array}$ \\
\hline Crcatinina mg/dl & $\begin{array}{c}1,2 \pm 0,2(20) b \\
(0,9-1,5)\end{array}$ & $\begin{array}{c}12 \pm 0,3(13) b \\
(0,0-1,9)\end{array}$ & $\begin{array}{l}1,2 \pm 0,1(43) b \\
(0,9 \cdot 1,6)\end{array}$ & $\begin{array}{c}1,4 \pm 0,2(49)_{\mathrm{a}} \\
(1,1-1,9)\end{array}$ \\
\hline
\end{tabular}

a b- Letras diferentes indicam diferença șignificativa em nlvel de e $=0,0.5$. 
Tabcla 3 - Eletrólitos séricos de 57 animais da especie Cebus apelfa, clinicamente sudios, anestesiados com cetamina, segundo sexo e idade, expressos em mèdia (X) e desvin padrăo (DP). Sło Paulo, 1995

\begin{tabular}{|c|c|c|c|c|}
\hline \multirow{2}{*}{ Parảmetros } & \multicolumn{2}{|c|}{ Jovens } & \multicolumn{2}{|c|}{ Adultos } \\
\hline & $\begin{array}{c}\text { Fẽmtas } \\
X \pm D P(n)\end{array}$ & $\begin{array}{r}\text { Maches } \\
X \pm D P(n)\end{array}$ & $\begin{array}{c}\text { Fc̀mcas } \\
X \pm 1) P(n)\end{array}$ & $\begin{array}{l}\text { Machos } \\
X \pm D P \text { (n) }\end{array}$ \\
\hline P mg/dl & $\begin{array}{c}5.0 \pm 1.4(10) \mathrm{a} \\
(3,7 * 7,4)\end{array}$ & $\begin{array}{c}5,2 \div 1,1(6) \mathrm{a} \\
(3,7-6,8)\end{array}$ & $\begin{array}{c}4,4 \pm 0.7(26) \mathrm{a} \\
(3,2-5,6)\end{array}$ & $\begin{array}{c}4.8 \pm 0,5(14) \mathrm{a} \\
(4,0-5,3)\end{array}$ \\
\hline Na mmola & $\begin{array}{l}141,0=7,5(8) b \\
(134,0-156,0)\end{array}$ & $\begin{array}{l}146,7 \pm 9,3(6) a b \\
(138.0-164.0)\end{array}$ & $\begin{array}{l}152.6 \pm 12.7(25) \mathrm{a} \\
(132,0-184,0)\end{array}$ & $\begin{array}{l}152.6 \pm 11,5(13) \mathrm{a} \\
(134,0 \cdot 166,0)\end{array}$ \\
\hline K mntolil & $\begin{array}{c}3,4 \pm 0,5(9) \mathrm{a} \\
(2.6 \cdot 4,3)\end{array}$ & $\begin{array}{l}3,5 \pm 0,5(6) \mathrm{a} \\
(2,6-4,2)\end{array}$ & $\begin{array}{c}3,8 \pm 0,5(25) \mathrm{a} \\
(2,7-4,7)\end{array}$ & $\begin{array}{c}3,8 \pm 0,5(13) \mathrm{a} \\
(3,2-5,0)\end{array}$ \\
\hline Ca meidl & $\begin{array}{l}8,2 \pm 0,7(10) \mathrm{a} \\
(7,6-9,5)\end{array}$ & $\begin{array}{l}8.4 \pm 1.0(6) \mathrm{a} \\
(7,6 \cdot 10,3)\end{array}$ & $\begin{array}{c}8,5+1,1(26) \mathrm{a} \\
(7.2-10,7)\end{array}$ & $\begin{array}{c}9,2 \pm 1,3(15) \mathrm{a} \\
(7,31-11,4)\end{array}$ \\
\hline $\mathrm{Cl} \mathrm{mmol} / \mathrm{l}$ & $\begin{array}{r}127.3 \pm 6,7(9) \mathrm{a} \\
(117.0-138.0)\end{array}$ & $\begin{array}{c}125,2 \pm 8,2(6) \mathrm{ab} \\
(114,0-135,0)\end{array}$ & $\begin{array}{l}124,6 \pm 5,7(26) \mathrm{ab} \\
(114,0-135,0)\end{array}$ & $\begin{array}{c}121,3+3,9(14) a b \\
(114,0-126,0)\end{array}$ \\
\hline
\end{tabular}

a, b - Letras diferentes indicam diferença significutiva $\mathrm{cm}$ nivel de $a=0,05$.

\section{DISCUSSÃO}

Ao analisar os resultados das provas de função hepática, nota-se que os animais jovens apresentam valores das enzimas fosfatase alcalina (ALP) e alanina aminotransferase (ALT) superiores aos dos animais adultos. RAO \& SHIPLEY (1970), trabalhando com algumas espécies de macacos, observaram diferenças relacionadas à idade; assim, encontraram níveis mais elevados de ALP em animais jovens e de pequeno porte e níveis mais baixos em animais velhos e de grande porte. Da mesma forma, macacos adultos jovens apresentaram valores de ALT significantemente superiores que os adultos. Os autores não observaram diferenças relacionadas à idade nos outros parâmetros séricos nos espécimes estudados.

Sabe-se que a atividade osteoblástica é exacerbada nos animais em fase de crescimento e, estando a ALP presente em tecido ósseo, é compreensível que os valores da referida enzima sejam mais elevados nos animais jovens (SCHMID \& Von FORSTNER, 1985).

AALT é uma enzima encontrada quase que exclusivamente no citoplasma dos hepatócitos, sendo que níveis elevados da mesma são indicativos, portanto, de injúria de parênquima hepático (SCHMID \& Von FORSTNER, 1985). Os valores elevados de ALT, nos animais jovens, podem ser atribuídos a uma certa imaturidade do parênquima hepático nos mesmos, o que determina uma maior fragilidade das membranas citoplasmáticas dos hepatócitos e, conseqüentemente, um maior extravazamento da citada enzima para a circulação periférica.

Os valores de AST obtidos no presente trabalho foram maiores nos machos jovens do que nos adultos. GRANA et al. (1988) também encontraram valores de AST mais elevados em animais jovens, especialmente nas fêmeas.

As enzimas hepáticas apresentaram uma grande variação dentro dos próprios grupos de animais, determinando um aumento do desvio padrão e, portanto, um aumento da faixa de normalidade destes parâmetros bioquímicos, observação esta também citada para outras espécies de primatas de pequeno e médio portes, semelhantes ao Cebus apella (Morrow \& Terrys, 1968a/1968b/1968c apud MITRUKA et al., 1977; Alstshuler \& Stowell, 1972 apud MITRUKA et al., 1977).

No que tange aos valores de proteínas totais, os resultados obtidos no presente trabalho estão em consonância com aqueles referidos por GRANA et al. (1988), sendo o citado parâmetro bioquímico mais elevado no grupo de fêmeas adultas. Por outro lado, em relação aos níveis de albumina, os resultados ora obtidos são diferentes daqueles encontrados por GRANA et al. (1988), sendo mais elevados no grupo das fêmeas jovens e dos machos adultos.

Em relação às provas de função renal, embora GRANA et al. (1988) não tenham encontrado diferença dos valores de uréia e creatinina nos diferentes grupos, observaram-se níveis de uréia superiores nos machos jovens do que nos adultos, de 
ambos os sexos, e valores de creatinina mais elevados nos machos adultos o que talvez possa ser relacionado ao fato dos animais machos apresentarem maior massa muscular.

Os resultados referentes aos níveis de bilirrubinas não foram analisados estatisticamente em função da amostragem reduzida. e outros não referidos necessitem talvez ser objeto de novos estudos, considerando-se uma maior amostragem.

\section{CONCLUSÕES}

Os resultados obtidos por meio da metodologia empregada no presente trabalho, analisados estatisticamente, permitem afirmar que:

a) a albumina apresenta níveis mais elevados no grupo das fêmeas jovens e dos machos adultos do nos machos jovens;

b) os níveis séricos de proteínas totais das fêmeas adultas são maiores do que o dos machos jovens;

c) as determinações de ALPe ALT são mais elevadas nos animais jovens que naqueles adultos, tanto machos quanto fêmeas;

d) os valores de AST nos machos jovens são mais altos do que nos machos adultos;

e) os valores de creatinina apresentam-se mais altos nos machos adultos;

f) os níveis de uréia são superiores nos machos jovens em relação aos adultos de ambos os sexos;

g) o sódio apresenta valores mais elevados nos machos e fêmeas adultos do que nas fêmeas jovens;

h) os valores de cloretos são maiores nas fêmeas jovens do que nos machos adultos;

i) em relação aos níves séricos de glicose, gama glutamiltransferase e dos eletrólitos fósforo, potássio e cálcio, não se observa qualquer variação significante entre os grupos.

\section{REFERÊNCIAS BIBLIOGRÁFICAS}

BENNET, J.S., GOSSET, K.A., McCARTHY, M.P., et al. Effects of ketamine hydrocloride on serum biochemical and hematologic variables in Rhesus monkeys (Macaca mulatta). Veterinary Clinical Pathology, Santa Barbara,v. 21, n.1, p. 15-18, 1992

BERGMEYER, H.U. Glutamate-oxaloacetate transaminase. In: BERGMEYER, H.U. Methods of enzymatic analysis Weiheim: Verlag Chemie, 1974. v. 2, Cap. 7 , p. 727-773.

BERTI, G., FOSSATI, P., ERIL, G.V.M., et al. Enzymatic colorimetric assay of inorganic phosphate. Clinical Chemistry, Winston Salem, v. 33, n. 2, p. 312, 1987.
BHARHAM, D., TRINDER, P. An improved colour reagent for the determination of blood glucose by oxydase system. The Analyst, London, v. 97, p. 142-145, 1972.

DIVILLARD, S.P., STUCCHI, A.F., TERSTRA, A.H.M., et al. The effects of dietary casein and soybean protein on plasma lipid levels in Cebus monkeys fed cholesterol-free or cholesterolenriched semi purified diets. Journal of Nutritional Biochemistry, Stoneham, v. 3, n. 2, p. 71-74, 1992.

DOUMAS, B.T., BIGGS, H.G., WATSON, W. Albumin standards and the measurement of serum albumin with bromocresol green. Clinica Chimica Acta, Amsterdam, v. 31, p. 87-96, 1971.

EISENMAN, A.J. A note on the Van Slyke method for the determination of chlorides in blood and tissue. Journal of Biological Chemistry, Baltimore, v. 82, n. 2, p. 411- 414, 1929.

FAKLEN, A.M., ROCHA, M.B. da, SIMON, F. Valores hematológicos e séricos de símios brasileiros, clinicamente sãos, mantidos em cativeiro. In: CONGRESSO BRASILEIRO DE PRIMATOLOGIA, 1, 1983. Belo Horizonte, MG. Anais... Belo Horizonte, MG, S. Ed. 1983, 402 p., p. 321-32.

FALASCA, C.A., GILI, M., GRANA, D., et al. Cronic myocardial damage in experimental T. cruzi infection of a new world primate, Cebus sp monkey. Revista do Instituto de Medicina Tropical de São Paulo, São Paulo, v. 32, n.3, p. 151-161, 1990

GORNALL, A.G., BARDAWILL, C.J., MAXIMA, M.D. Determination of serum proteins by means of biuret reaction. Journal of Biological Chemistry, Baltimore, v. 177, n. 2, p. 751-766, 1949 .

GRANA, D., MINO, J., HERLO, A., et al. Normal laboratory parameters of the new world primate Cebus apella (Capuchin monkey). Revista de Medicina Veterinária, Buenos Aires, v. 69, n. 3, p. 156-160, 1988.

JENDRASSIK, L., GROF, P. Vereentachte photometrische methoden zur bestimmung des blutbilirrubins. Biochemische Zeitschrift, Berlin, v. 297, n.1-2, p. 81-89, 1938.

KLOSLA, P., HAYES, K.C. Comparison between the effects of dietary saturated (16:0), monosaturated (18:1) and polyunsaturated fatty acids on plasma lipoprotein metabolism. American Journal of Clinical Nutrition, Bethesda, v. 55 , n.1, p. 51-62, 1992.

LUSTGARTEN, J.A., WENK, R.E. Simple, rapid, kinetic method for serum creatinine measurement. Clinical Chemistry, Winston Salem, v. 18, n. 11, p. 1419-1422, 1972

MALCHIODI, E.L., CARBONETTO, C.H., GRANA, D., $\boldsymbol{e}$ t al. Imuneresponse against $\boldsymbol{T}$. cruzi antigens in Cebus apella monkeys. Tropical Medicine and Parasitology, Buenos Aires, v. 44, n. 2, p. 86-90, 1993.

MARTIN, D.P. Introduction and identification. In: FOWLER, M.E Zoo and Wild Animal Medicine. 2. ed. Philadelphia: Saunders, 1986. Cap. 44: Primates: p. 658-673.

MITRUKA, B.M., RAWNSLEY, H.M., VADEHRA, B.V. Clinical, biochemical and hematological reference values in normal experimental animals. New York: Masson Publishing, 1977. p. $152-160$ 
PENTILlA, I.M., JOKELA, H.A., VITALA, A.J., $\boldsymbol{e} \boldsymbol{t} \boldsymbol{a l}$. Activities of aspartato and alanino aminotransferase and alkaline phosphatase in sera of healthy subjects. The Scandinavian Journal of Clinical and Laboratory Investigation, Oslo, v. 35, n. 3, p. 275$284,1975$.

PRONKUK, A., PATTON, G.M., STEPHAN, Z.F., et al. Species variation in the atherogenic profile of monkeys: relantionship between dietary fats lipoprotein and platelets aggregation. Lipids, Champaign,v. 26, n. 3, p. 213-222, 1991.

RAO, G. N., SHIPLEY, E. G. Data on selected clinical blood chemistry tests of adult female Rhesus monkeys (M. mulatta). Laboratory Animal Care, Pennsylvania,v. 20, p. 226-230, 1970.

SARKAR, B.C., CHAUHAN, U.P.S. A new method for determining micro quantities of calcium in biological material.
Analytical Biochemistry, New York, v. 20, n. 1, p. 155-166, 1967.

SCHMID, M., Von FORSTNER. Laboratory testing in veterinary medicine diagnosis and clinical monitoring. 3 . ed. Mannheim: Boehringer Mannheim. 1985, p. 25-48.

SZASZ, G. Kinetic photometric method for serum gama-glutamil transpeptidase. Clinical Chemistry, Winston Salem, v.15, n. 2, p. 124-136, 1969.

TIFFANY, T.O., JANSEN, J.M., BRITO, C.A., et al. Enzymatic kinetic rate and end-point analysis of substrate by use of a GEMSAEC fast analysis. Clinical Chemistry, Winston Salem, v. 18 , n. 8 , p. $829,1972$.

WEISSMAN, N., PILEGGI,V.J. Iones inorgánicos. In: HENRY, R.J., CANNON, D.C., WINKELMAN, J.W. Quimica Clinica. Bases y tecnicas. Barcelona: JIMS, 1980. v. 1, Cap 19, p. 643-762. 